\title{
Inequality of Opportunity in Daycare and Preschool Services in Brazil ${ }^{1}$
}

\author{
Miguel N. Foguel \\ (IPEA) \\ Fernando A. Veloso \\ (IBRE/FGV)
}

April 2012

\begin{abstract}
In this paper we measure inequality of opportunity in daycare and preschool services in Brazil. For this purpose, we construct an opportunity index that modifies the human opportunity index proposed in the literature and used in Barros et al. (2009) to measure inequality in basic opportunities in Latin America and the Caribbean. Specifically, we construct an opportunity measure that includes not only attendance but also parental choice not to enroll children in daycare or preschool, using data from a supplementary questionnaire included in the 2006 version of Pesquisa Nacional por Amostra de Domicílios (PNAD). The results show that there are large differences between our opportunity index and the human opportunity index for children aged 0-3 years old and considerably smaller differences for children aged 4-6 years old, which suggests that preschool may be closer to a basic opportunity than daycare.
\end{abstract}

\footnotetext{
${ }^{1}$ We are grateful to Ricardo Paes de Barros, Jere Behrman, Cesar Bouillon, John Hoddinott, Florencia Lopez-Boo, Rosane Mendonça, Hugo Ñopo, Cristine Pinto, Daniel Santos, and Raul Silveira for comments and suggestions. Samuel Franco provided outstanding research assistance. All remaining errors are our own.
} 


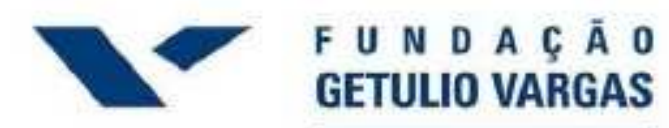

IBRE

Instituto Brasileiro

de Economia

\section{Resumo}

Este artigo mensura o grau de desigualdade de oportunidades na creche e pré-escola no Brasil. Com este objetivo, construímos um indicador de oportunidade que modifica o índice de oportunidade humano utilizado em Barros et al. (2009) para medir desigualdade de oportunidades básicas na América Latina e Caribe. Especificamente, construímos uma medida de oportunidade que inclui não somente a taxa de atendimento, mas também a escolha dos pais de não matricular seus filhos na creche ou pré-escola, usando dados de um suplemento incluído na Pesquisa Nacional por Amostra de Domicílios (PNAD) de 2006. Os resultados mostram que existe uma grande diferença entre o nosso indicador de oportunidade e o índice de oportunidade humana para crianças na faixa etária entre 0 e 3 anos de idade. As diferenças são consideravelmente menores na faixa etária entre 4 e 6 anos, o que sugere que a préescola está mais próxima de uma oportunidade básica que a creche.
\end{abstract}




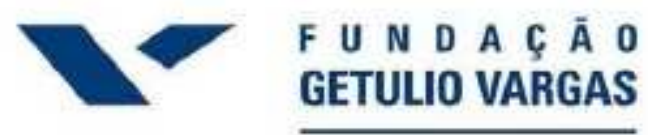

IBRE

Instituto Brasileiro

de Economia

\section{Introduction}

A large body of literature makes the case for investment in early childhood development (ECD). Research in neuroscience has established that learning is easier in early childhood than later in life (see a discussion of the evidence in Cunha et al., 2006 and Cunha and Heckman, 2009). Other studies have argued that the returns to human capital investment in early childhood are higher than later in life because the beneficiaries have a longer time to reap the benefits (Becker, 1993). Carneiro and Heckman (2003) also argue that investments in human capital have dynamic complementarities, in the sense that earlier investments increase the returns to later investment. They also claim that there is no tradeoff between equity and efficiency in early childhood investments, whereas for later investments an increase in efficiency is usually associated with more inequality.

This evidence suggests that ECD interventions and, in particular, daycare and preschool have potentially high returns. Consistent with this evidence, in many countries policymakers have been increasing investments in ECD programs. In Brazil, in particular, several modifications in the legislation related to daycare and preschool have been enacted since the late eighties, reflecting a continuous increase in the importance attached by society to the provision of pre-primary education.

For instance, the Constitution of 1988 established that all children aged between 0 and 6 years old have the right to free public daycare and preschool services. In 1996, the Lei de Diretrizes e Bases da Educação (LDB) established daycare and preschool as part of Basic Education, in addition to primary and secondary schooling. Even though only primary education was mandatory, the inclusion of early childhood education indicated that it was viewed as a priority. 


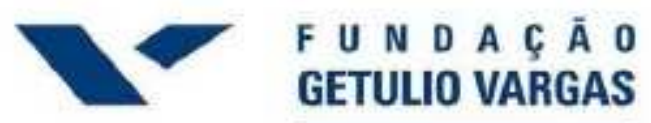

IBRE

Instituto Brasileiro

de Economia

In 2006, the age of entry in primary school was lowered from 7 to 6 years old, indicating that early childhood education has been increasingly viewed as compulsory. This pattern was confirmed by the congressional approval in November of 2009 of a Constitutional Amendment that established mandatory enrollment in preschool for children aged 4-5.

In 2007, the Fundo de Manutenção e Desenvolvimento da Educação Básica e de Valorização dos Profissionais da Educação (FUNDEB) was created to provide funding for basic education in Brazil. One important innovation of FUNDEB relative to the previous educational fund (FUNDEF) is that it included preschool and daycare, thus becoming an important source of funds for pre-primary expenditures.

The main goal of this paper is to measure inequality of opportunity in daycare and preschool (D\&P) services in Brazil. Barros et al. (2008a) and Barros et al. (2008b) have recently proposed a synthetic measure of inequality of opportunity in basic services for children called the human opportunity index. Barros et al. (2009) used this methodology to measure inequality in access to basic opportunities in Latin America and the Caribbean.

One main difficulty in making the concept of opportunity operational is that, even though it is associated with the possibility of making choices, the observed outcomes are usually the actual choices. For instance, in the construction of the human opportunity index, access to school services is assumed to be equivalent to actual attendance. The authors argued that, in the case of basic goods and services that are critical for the full development of a child, the concept of opportunity can be made operational by measuring children's use of these services. They considered as basic opportunities variables related to education (completion of sixth grade on time and school attendance at ages 10-14) and housing conditions (access to clean water, sanitation and electricity). 


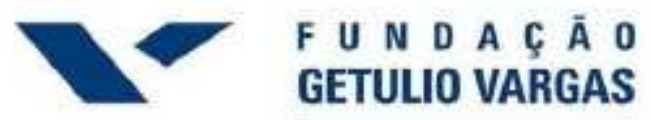

IBRE

Instituto Brasileiro

de Economia

However, it is not clear whether to attend daycare or preschool should be considered a basic opportunity in the sense it has been defined in Barros et al. (2009). In particular, the Brazilian legislation regarding daycare and preschool states that parents who want their children to attend daycare and preschool should have the option to do so. For this reason, in this paper we modify the computation of the human opportunity index and measure opportunity as having the option to attend daycare or preschool. It thus includes not only actual attendance but also the choice not to enroll children in daycare or preschool.

In this paper we use data from Pesquisa Nacional por Amostra de Domicílios (PNAD), the main Brazilian household survey. In order to construct the opportunity index for daycare and preschool we use a supplementary questionnaire that was included in the 2006 version of PNAD. This supplement contains a specific question for households whose children were not going to school at the time of the survey. It asks the main reason why children were not attending daycare or preschool, one of the reasons being that the parents did not want their children to attend daycare or preschool. Given that the measure of opportunity used here incorporates the possibility that parents prefer not to send their children to pre-primary schools, the existence of this explicit option in the questionnaire is particularly suitable for our purposes.

The results show that there are large differences between our opportunity index and the human opportunity index for children aged 0-3 years old and considerably smaller differences for children aged 4-6 years old. This is due to the fact that there is a significant fraction of parents that choose not to enroll their children in daycare. On the other hand, as children's age increases, the proportion of children that do not attend school by parental choice declines significantly, which suggests that preschool may be closer to a basic opportunity than daycare. 


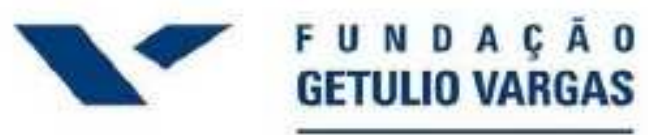

IBRE

Instituto Brasileiro

de Economia

This paper is organized as follows. In section 2 we present the methodology used to construct our opportunity index. Section 3 describes the PNAD data and, in particular, the 2006 supplement. Section 4 presents results for our opportunity index, and compares it with the human opportunity index in order to understand to what extent non-attendance to daycare or preschool is a voluntary decision. Section 5 presents a profile of the most-disadvantaged and least-disadvantaged circumstance groups, which may be relevant for policy purposes. The main conclusions are presented in Section 6.

\section{Methodology}

\subsection{Construction of the Opportunity Index}

The analytical framework presented in this subsection is the same as that used to construct the human opportunity index in Barros et al. (2008a) and Barros et al. (2008b), and used by Barros et al. (2009) to measure inequality in access to basic opportunities in Latin America and the Caribbean. ${ }^{2}$

The main difference is in the way opportunity is measured. Whereas in the human opportunity index it is measured by actual school attendance, our opportunity index includes not only attendance but also children whose parents chose not to enroll them in daycare or preschool.

Let I(i) be an indicator of whether child $\mathrm{i}=1,2, \ldots, \mathrm{n}$ has the opportunity to attend daycare or preschool (D\&P) at a point in time. Specifically, let I(i) $=1$ for those children that have attended daycare or preschool or did not attend by parental choice and $\mathrm{I}(\mathrm{i})=0$, otherwise. When $\mathrm{I}(\mathrm{i})=1 \forall \mathrm{i}$, there are opportunities for all children, in which case $\mu=P[I=1]=1$.

\footnotetext{
${ }^{2}$ The human opportunity index is inspired by the social welfare function proposed by Sen (1976). Roemer (1998) provides an extensive discussion of conceptual and measurement issues related to equality of opportunity. See Peragine (2011) for a recent review of Barros et al. (2009).
} 


\section{$F U N$ D A ÇÄ Ä O
GETULIO VARGAS}

IBRE

Instituto Brasileiro

de Economia

Since full opportunity occurs only if $\mu=1$, it seems reasonable to measure progress towards opportunities for all as $\mu$ shifts towards unity. However, whenever $\mu$ is away from unity it is important to take into account how the available opportunities are allocated across children. Specifically, one has to consider not only the overall proportion of children having the opportunity but also whether the opportunities are distributed according to the equality of opportunity principle.

One way the equality of opportunity principle is violated occurs when opportunities are allocated to children according to a set of their characteristics that should not be related to access to D\&P services. For instance, having access to services should not be associated with the fact that a child is black or white, lives in a rural or urban area, or with the schooling of his/her parents. In the literature, the set of factors that are beyond the children's control and ought not to be related to outcomes or access to services are called circumstances. ${ }^{3}$ In this study, we will assume that equality of opportunity prevails if and only if circumstances are not related to the opportunity to use D\&P services.

Formally, let $\mathrm{X}(\mathrm{i})$ be a vector that represents the set of all circumstances for children i. Define $\mathrm{p}(\mathrm{x}) \equiv \mathrm{P}[\mathrm{I}=1 \mid \mathrm{X}=\mathrm{x}]$ as the coverage rate specific to the circumstance group $\mathrm{x} .{ }^{4}$ We then state that equality of opportunity prevails whenever $\mathrm{p}(\mathrm{x})=\mu$ for all possible circumstance groups.

\footnotetext{
${ }^{3}$ In the equality of opportunity literature circumstances contrast with the set of factors that are under the individual's responsibility, usually called efforts (see, e.g., Roemer (1998), Barros et al. (2009), Checchi and Peragine (2010), and Pistolesi (2009)). Note that, although efforts can be correlated with circumstances in the case of adults, this is not an issue in the case of children.

${ }^{4}$ In this paper, the coverage rate denotes not only the actual use of a service but also the choice not to use it.
} 


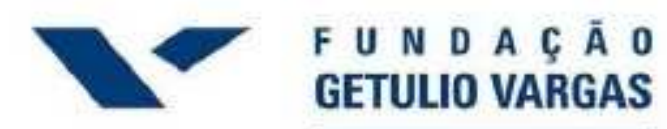

IBRE

Instituto Brasileiro

de Economia

However, we typically observe coverage rates of some circumstance groups to be below or above the overall coverage rate. In that case, the principle of equal opportunity is violated. One way we could measure the unequal allocation of opportunities is through

$$
T=\int_{p(x)>\mu}(p(x)-\mu) d F_{X}(x)
$$

where $F_{X}($.$) represents the cumulative distribution of circumstance groups. The scalar$ measure $\mathrm{T}$ corresponds to the total number of opportunities that violates the equality of opportunity principle expressed as a proportion of the total number of opportunities required for full coverage. For the specific case we are studying, $\mathrm{T}$ gives the proportion of D\&P opportunities that are unequally allocated relative to the full opportunity case.

If we divide $\mathrm{T}$ by $\mu$, we obtain the number of unequally allocated opportunities as a proportion of the total number of available opportunities. This ratio, denoted by $\mathrm{D}$, is a measure of the inequality of opportunity, known as the dissimilarity index in the sociological literature, and is given by:

$$
D=\frac{T}{\mu}
$$

$\mathrm{T}$ and $\mathrm{D}$ provide measures of inequality in the allocation of opportunities. However, one may be interested in measuring inequality of opportunities in terms of the distance towards the accomplishment of the ideal of opportunity for all. To capture this idea, Barros et al. (2008a, 2008b) proposed a measure of opportunity given by

$$
O \equiv \mu-T=\int p(x) d F_{X}(x)-\int_{p(x)>\mu}(p(x)-\mu) d F_{X}(x) .
$$




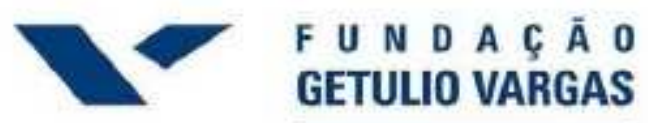

IBRE

Instituto Brasileiro

de Economia

The measure $O$ will be the opportunity index used in this paper. As discussed above, it differs from the human opportunity index used in Barros et al. (2009) because it measures opportunity as the extent to which parents have the option to enroll their children in daycare or preschool rather than attendance per se.

Notice that since $O$ discounts from the available opportunities all those that are unequally allocated, it can be seen as a measure of the distance towards the ideal of opportunity for all. Using (2) and (3), we can express the opportunity index as a function of $\mu$ and the dissimilarity index:

$$
O \equiv \mu(1-D)
$$

Before we explain how we intend to estimate the opportunity index, we need to present some further analytical steps. First, notice that since

$$
\mu=\int_{p(x) \leq \mu} p(x) d F_{X}(x)+\int_{p(x)>\mu} p(x) d F_{X}(x)
$$

it follows that

$$
\int_{p(x)>\mu}(p(x)-\mu) d F_{X}(x)=\int_{p(x) \leq \mu}(\mu-p(x)) d F_{X}(x),
$$

which implies that $\mathrm{T}$ can also be written as

$$
T=\int_{p(x) \leq \mu}(\mu-p(x)) d F_{X}(x) .^{5}
$$

\footnotetext{
${ }^{5}$ Note that $\mathrm{T}$ can also be interpreted as the total number of opportunities that the "vulnerable" circumstance groups (i.e. those with $p(x) \leq \mu$ ) need for their specific coverage rates to attain the overall average, expressed as a proportion of the total number of opportunities required for full coverage.
} 


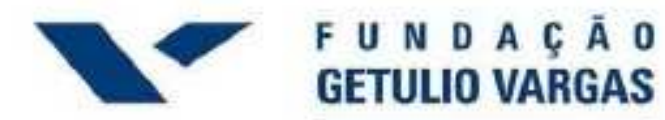

\section{IBRE}

Instituto Brasileiro

de Economia

Second, since

$E|p(X)-\mu|=\int_{p(x) \leq \mu}(\mu-p(x)) d F_{X}(x)+\int_{p(x)>\mu}(p(x)-\mu) d F_{X}(x)$,

it follows from (1) and (5) that

$T=\frac{1}{2} E|p(X)-\mu|$

Hence, we can write from (2) and (6) that:

$D=\frac{1}{2 \mu} E|p(X)-\mu|$

We will use (4) and (7) as the basis for our empirical work.

\subsection{Empirical Methods}

Let I denote a child from the population and $x_{i}=\left(x_{1 i}, \ldots, x_{m i}\right)$ a vector of $m$ variables that measures child i's circumstances. Let $I_{i}=1$ if child $i$ had the opportunity to attend D\&P services and $\mathrm{I}_{\mathrm{i}}=0$ otherwise. As discussed in the previous subsection, we define opportunity as the option to attend daycare or preschool. 


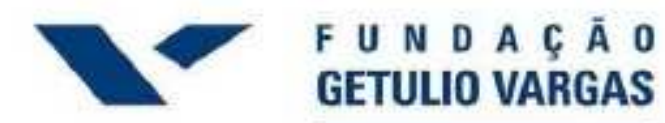

\section{IBRE}

Instituto Brasileiro

de Economia

The estimation of $\mathrm{O}$ is fundamentally based on the group specific coverage rates, $\mathrm{p}(\mathrm{X})$. Though these conditional probabilities can be estimated through non-parametric or semi-parametric methods, we will rely on a fully parameterized case. Specifically, estimation will be based on the following logistic model

$$
\operatorname{Ln}\left(\frac{P\left(I=1 \mid X=\left(x_{1}, \ldots, x_{m}\right)\right)}{1-P\left(I=1 \mid X=\left(x_{1}, \ldots, x_{m}\right)\right)}\right)=\sum_{k=1}^{m} h_{k}\left(x_{k}\right),
$$

where $x_{k}$ represents the $k^{\text {th }}$-dimension of circumstances. The functions $h_{k}$ can be chosen according to the needs of each dimension. In all cases, however, we assume all functions are linear in parameters, i.e. $h_{k}\left(x_{k}\right)=x_{k} \beta_{k}$.

From the estimation of this logistic regression one obtains estimates of the parameters, $\hat{\beta}_{k}$, which are then used to compute $\hat{p}_{i}$, the predicted probability of having the option to attend a D\&P establishment for each child $\mathrm{i}$ :

$$
\hat{p}_{i}=\frac{\operatorname{Exp}\left(\sum_{k=1}^{m} x_{k i} \hat{\beta}_{k}\right)}{1+\operatorname{Exp}\left(\sum_{k=1}^{m} x_{k i} \hat{\beta}_{k}\right)}=\frac{\operatorname{Exp}\left(x_{i} \hat{\beta}\right)}{1+\operatorname{Exp}\left(x_{i} \hat{\beta}\right)}
$$

With estimates of the $\hat{p}_{i}^{\prime} s$ in hand, we can calculate $\hat{\mu}=\sum_{i=1}^{n} w_{i} \hat{p}_{i}$, where $w_{i}$ represents the sampling weight and $n$ is the total number of children in the sample.

We can obtain an estimate of the dissimilarity index, $\mathrm{D}$, given by

$$
\hat{D}=\frac{1}{2 \hat{\mu}} \sum_{i=1}^{n} w_{i}\left|\hat{p}_{i}-\hat{\mu}\right| \text {. }
$$




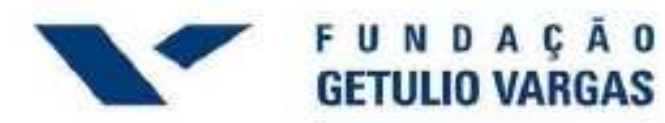

IBRE

Instituto Brasileiro

de Economia

Our estimate of the opportunity index is given by

$\hat{O} \equiv \hat{\mu}(1-\hat{D})$

Barros et al. (2008a) show that $\hat{D}$ is a consistent estimator of $D$ and Barros et al. (2008b) show that $\hat{O}$ is a consistent estimator of $O$.

\section{Data Source}

The data source we use is the Pesquisa Nacional por Amostra de Domicílios (PNAD), the main Brazilian National Household Survey. PNAD is fielded annually since 1976 by the Brazilian Bureau of Census (Instituto Brasileiro de Geografia e Estatística - IBGE) and has the broadest coverage among the Brazilian household surveys. PNAD is a cross-section sample that interviews around 100,000 households (about 400,000 individuals) over the entire territory of the country.

PNAD's basic questionnaire covers the main dimensions of socioeconomic conditions of households, including family structure, education, labor market status of household members and their income. This broad coverage is convenient because it allows us to use a large set of characteristics to estimate the probability of a child having the opportunity to attend daycare or preschool services.

Questions about attendance to schools appear in the data since 1981. However, it is only since 1996 that PNAD included a question about attendance to pre-primary education. The distinction between daycare (for children between 0 and 3 years old) and 


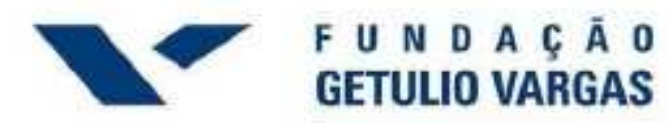

IBRE

Instituto Brasileiro

de Economia

preschool (for children between 4 and 6 years old ${ }^{6}$ ) was introduced in the questionnaire since 2001. This question about attendance to pre-primary education belongs to the survey's basic questionnaire and asks the respondent whether or not children in the household are actually attending daycare or preschool (at the time of the survey, usually in September).

As discussed in the previous section, our measure of opportunity also includes children whose parents had the option to enroll them at daycare or preschool but chose not to do so. In order to construct the opportunity index for daycare and preschool we use a supplementary questionnaire that was included in the 2006 version of PNAD. ${ }^{7}$ This supplement contains a specific question that is answered by the respondents whose children were not going to school at the time of the survey. It asks the main reason why children were not attending daycare or preschool, one of the possible reasons being that the parents did not want their children to attend daycare or preschool (see below for a list of the other options). Given that the measure of opportunity used here incorporates the possibility that parents prefer not to send their children to pre-primary schools, the existence of this explicit option in the questionnaire is particularly suitable for our purposes.

Hence, in all measures we compute, we include two groups of children that had the opportunity to attend daycare or preschool: children who actually attended and those that did not attend because their parents did not want to. The children that do not belong to these two groups will be taken as a group that, for some reason, did not have the opportunity to use pre-primary school services.

\footnotetext{
${ }^{6}$ Since 2006 the age of entry in primary school was lowered from 7 to 6 , with a transition period until 2010.

${ }^{7}$ A similar supplementary questionnaire was included in the 2004 version of PNAD. All results in this paper were also obtained for 2004. They are very similar to the ones presented here and can be obtained from the authors upon request.
} 


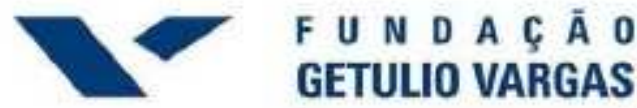

IBRE

Instituto Brasileiro

de Economia

Table 1 displays, for each age, the proportion of children that attended daycare or preschool in 2006. The first point to notice is that attendance to a pre-primary school establishment was monotonically increasing with age until age 5. In particular, attendance to daycare was particularly low up to age 2 and increased to $35 \%$ for children with 3 years of age. At age 4, 58\% of children attended preschool and attendance was around $3 / 4$ at age 5. However, at age 6 this proportion dropped to $63 \%$. This was due to the fact that some parents decided to enroll their 6-year old children in primary school instead of preschool.

Table 1: Proportion of children that attended daycare or preschool by age - 2006 $(\%)$

\begin{tabular}{|c|c|c|c|c|c|c|c|c|}
\hline & \multicolumn{7}{|c|}{ Age } & \multirow[b]{2}{*}{ Total } \\
\hline & 0 & 1 & 2 & 3 & 4 & 5 & 6 & \\
\hline Attended & 2.2 & 7.3 & 17.9 & 34.6 & 58.0 & 75.1 & 63.2 & 38.4 \\
\hline Sample & 6220 & 6180 & 6449 & 6499 & 6660 & 6981 & 7474 & 46463 \\
\hline
\end{tabular}

Source: Authors' calculations based on PNAD 2006.

Table 2 presents, for each age, the distribution of children that did not attend daycare or preschool in 2006 according to the main reason for non-attendance. As it can be seen, the most relevant reasons for non-attendance were (in ascending order): (1) lack of money for school expenses, (2) lack of vacancy at a school or daycare establishment, (3) no school or daycare close to home, (4) parents do not want children to attend, and (5) other motives. ${ }^{8}$ The first three reasons [(1), (2), and (3)] can be seen as restrictions families face to send their children to daycare or preschool, the first corresponding to lack of own economic resources and the following two as lack of vacancies. Reason (4) is the one we include in our measure of opportunity as the case in

\footnotetext{
${ }^{8}$ All other reasons together do not sum up to 5 percent for all ages. The questionnaire included four other reasons, "help in domestic chores", "work or looking for work", "parents prefer that the child work", and "concluded aimed degree", that are not applicable to children under 6, though they appear residually due to misresponse.
} 


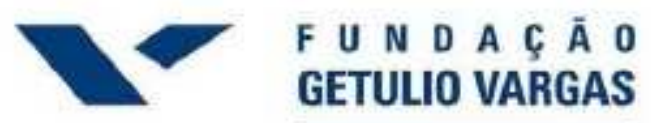

IBRE

Instituto Brasileiro

de Economia

which children did not attend daycare or preschool by parental choice. However, it is unclear which motives belong to the category "other motives", especially if we take into account that the other options seem to cover the most relevant reasons for a child not to attend a pre-primary school. ${ }^{9}$

One important question is what it means for parents not to want their children to attend daycare or preschool and to what extent this response represents a choice that is fundamentally different from other responses that are related to lack of resources or of vacancies at a preschool or daycare establishment. ${ }^{10}$ Our interpretation is that parents who responded that they do not want their children to attend school made a voluntary choice based on their preferences, budget constraint and prices, which is not constrained by lack of resources or vacancies. However, it is conceivable that two families with identical situations might answer the question differently, one referring to "want" and the other to "lack of income".

A piece of evidence that the parental response "do not want children to attend" represents a choice that is qualitatively different from the other options is that the proportion of responses in this category declines significantly with age, whereas the opposite happens for responses related to lack of income or vacancies. In fact, about $40 \%$ of children in their first two years of life did not attend school because their parents "do not want children to attend", while this proportion drops to around $30 \%$ at age 5 and to $21 \%$ at age 6 . On the other hand, whereas less than $5 \%$ of children in their first two years of life did not attend school due to "lack of vacancies at a school or daycare establishment", this proportion increases to $15 \%$ at age 5 and $17 \%$ at age $6 .{ }^{11}$

\footnotetext{
${ }^{9}$ It is noticeable, however, the absence of a motive related to the (perceived) quality of D\&P services.

${ }^{10} \mathrm{We}$ are grateful to Jere Behrman for raising this issue.

${ }^{11}$ A similar pattern is observed for the responses "lack of money for school expenses" and "no school or daycare close to home".
} 


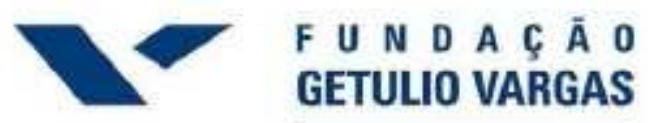

IBRE

Instituto Brasileiro

de Economia

Table 2: Distribution of children that did not attend daycare or preschool according to the main reason for non-attendance - by age - $2006(\%)$

\begin{tabular}{|c|c|c|c|c|c|c|c|c|}
\hline \multirow[b]{2}{*}{ Main Reason } & \multicolumn{7}{|c|}{ Age } & \multirow[b]{2}{*}{ Total } \\
\hline & 0 & 1 & 2 & 3 & 4 & 5 & 6 & \\
\hline Lack of school buses & 0.1 & 0.0 & 0.2 & 0.3 & 0.7 & 1.0 & 3.2 & 0.3 \\
\hline $\begin{array}{l}\text { Lack of money for school expenses (tuition, } \\
\text { school material, clothing, etc.) }\end{array}$ & 0.5 & 1.3 & 1.8 & 2.8 & 4.0 & 3.7 & 4.5 & 2.0 \\
\hline Lack of documentation & 0.1 & 0.1 & 0.2 & 0.3 & 0.3 & 0.9 & 1.7 & 0.3 \\
\hline No school or daycare close to home & 5.4 & 8.4 & 10.5 & 13.3 & 14.4 & 17.7 & 13.6 & 10.3 \\
\hline $\begin{array}{l}\text { Lack of vacancy at a school or daycare } \\
\text { establishment }\end{array}$ & 2.8 & 4.4 & 7.0 & 8.8 & 11.9 & 14.8 & 16.7 & 7.0 \\
\hline No one can take the child to school & 0.2 & 0.3 & 0.3 & 0.7 & 0.8 & 0.9 & 1.4 & 0.4 \\
\hline Illness or incapacity & 0.7 & 0.9 & 1.1 & 1.3 & 2.0 & 3.2 & 6.6 & 1.4 \\
\hline $\begin{array}{l}\text { Did not want to attend school or daycare } \\
\text { because of problems with school principal, } \\
\text { teacher, friends, etc. }\end{array}$ & 0.4 & 0.5 & 0.4 & 1.2 & 2.1 & 2.3 & 3.0 & 0.9 \\
\hline Dismissed from school or daycare & 0.0 & 0.0 & 0.0 & 0.1 & 0.0 & 0.2 & 0.0 & 0.0 \\
\hline School or daycare does not offer higher degrees & 0.2 & 0.3 & 0.3 & 0.3 & 0.5 & 0.6 & 0.9 & 0.4 \\
\hline Parents do not want children to attend & 40.5 & 39.5 & 36.9 & 32.8 & 31.1 & 29.4 & 20.6 & 36.2 \\
\hline Other motives & 49.2 & 44.1 & 41.4 & 38.2 & 32.1 & 25.1 & 27.6 & 41.0 \\
\hline Sample & 6103 & 5793 & 5398 & 4288 & 2896 & 1696 & 757 & 26931 \\
\hline
\end{tabular}

Source: Author's calculations based on PNAD 2006.

Another piece of evidence is provided by the relationship between the main reasons for non-attendance and per capita family income. Table 3 shows the distribution of children according to the main reason for non-attendance within each quintile of the per capita family income distribution in 2006. As expected, the proportion of children for which the main reason is related to lack of income or vacancies declines significantly with family income. Also noticeable is the decline in the category "other 


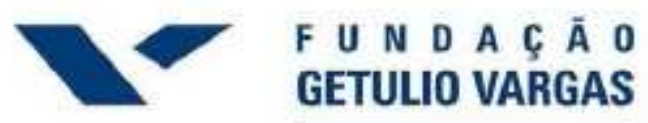

IBRE

Instituto Brasileiro

de Economia

motives", which suggests that it in fact captures lack of opportunities. In stark contrast with these patterns, the proportion of children for which the main reason for nonattendance is "parents do not want children to attend" increases with family income.

For instance, "parents do not want children to attend" was the main reason for non-attendance for $28 \%$ of children aged 0-3 years old in the lowest income quintile, whereas "lack of money for school expenses", "lack of vacancy at a school or daycare establishment", "no school or daycare close to home" and "other motives" accounted together for $69 \%$ of responses. In the highest income quintile, "parents do not want children to attend" was the main reason for non-attendance for $55 \%$ of children, whereas the aggregated proportion for the categories related to lack of resources or vacancies was $42 \%$. Similar patterns are observed for children aged 4-6 years old. 


\section{$1-$ \\ GETULIO VARGAS}

IBRE

Instituto Brasileiro

de Economia

Table 3: Distribution of children that did not attend daycare or preschool according to the main reason for non-attendance within per capita family income quintile - by age - 2006 (\%)

\begin{tabular}{|c|c|c|c|c|c|}
\hline \multirow[b]{2}{*}{ Age } & \multicolumn{5}{|c|}{ Income Quintiles } \\
\hline & 1 & 2 & 3 & 4 & 5 \\
\hline \multicolumn{6}{|l|}{$0-3$ years old } \\
\hline Lack of school buses & 0.2 & 0.2 & 0.1 & 0.0 & 0.0 \\
\hline $\begin{array}{l}\text { Lack of money for school expenses (tuition, school } \\
\text { material, clothing, etc.) }\end{array}$ & 1.6 & 1.8 & 1.3 & 1.5 & 0.7 \\
\hline Lack of documentation & 0.3 & 0.1 & 0.0 & 0.1 & 0.0 \\
\hline No school or daycare close to home & 13.6 & 7.9 & 5.8 & 4.4 & 2.6 \\
\hline Lack of vacancy at a school or daycare establishment & 5.4 & 6.7 & 6.2 & 4.8 & 2.1 \\
\hline No one can take the child to school & 0.4 & 0.3 & 0.4 & 0.4 & 0.1 \\
\hline Illness or incapacity & 1.0 & 1.0 & 0.8 & 0.9 & 1.2 \\
\hline $\begin{array}{l}\text { Did not want to attend school or daycare because of } \\
\text { problems with school principal, teacher, friends, etc. }\end{array}$ & 0.7 & 0.4 & 0.5 & 0.6 & 1.3 \\
\hline Dismissed from school or daycare & 0.0 & 0.0 & 0.0 & 0.0 & 0.0 \\
\hline School or daycare does not offer higher degrees & 0.3 & 0.3 & 0.2 & 0.2 & 0.4 \\
\hline Parents do not want children to attend & 28.3 & 38.4 & 46.9 & 50.0 & 54.9 \\
\hline Other motives & 48.2 & 42.9 & 37.8 & 37.2 & 36.9 \\
\hline \multicolumn{6}{|l|}{ 4-6 years old } \\
\hline Lack of school buses & 1.4 & 0.6 & 1.1 & 1.4 & 0.0 \\
\hline $\begin{array}{l}\text { Lack of money for school expenses (tuition, school } \\
\text { material, clothing, etc.) }\end{array}$ & 4.2 & 4.4 & 3.6 & 4.7 & 2.5 \\
\hline Lack of documentation & 1.0 & 0.3 & 0.3 & 0.1 & 0.0 \\
\hline No school or daycare close to home & 19.3 & 12.0 & 8.9 & 6.3 & 7.8 \\
\hline Lack of vacancy at a school or daycare establishment & 11.5 & 16.0 & 15.9 & 16.9 & 11.3 \\
\hline No one can take the child to school & 0.8 & 1.0 & 1.1 & 0.9 & 0.0 \\
\hline Illness or incapacity & 3.1 & 3.6 & 2.3 & 2.5 & 4.2 \\
\hline $\begin{array}{l}\text { Did not want to attend school or daycare because of } \\
\text { problems with school principal, teacher, friends, etc. }\end{array}$ & 2.3 & 2.3 & 3.2 & 2.4 & 2.7 \\
\hline Dismissed from school or daycare & 0.1 & 0.0 & 0.0 & 0.0 & 0.0 \\
\hline School or daycare does not offer higher degrees & 0.5 & 0.7 & 0.1 & 1.5 & 0.8 \\
\hline Parents do not want children to attend & 23.1 & 32.1 & 38.8 & 43.6 & 52.8 \\
\hline Other motives & 32.8 & 26.9 & 24.6 & 19.6 & 18.0 \\
\hline
\end{tabular}

Source: Author's calculations based on PNAD 2006.

Note: The poorest income quintile is 1 and the richest is 5 . 


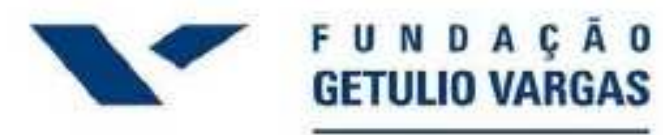

IBRE

Instituto Brasileiro

de Economia

In this study a child's circumstances will be defined by the following variables: (i) gender, (ii) race (iii) child's area of residence (urban or rural; geographical region; metropolitan area), (iv) number of years of schooling of the family head; (v) per capita family income; (vi) either single-parent or two-parent household, and (vii) number of siblings aged 0-16. ${ }^{12}$ Barros et al. (2009) used similar variables in their study of inequality of opportunity in Latin America and the Caribbean, but they did not include race and detailed location information because they were not present in all nationally representative surveys used in their analysis. ${ }^{13}$ Since PNAD has detailed information on race and location, we will be able to include these important circumstances in our study.

\section{Main Results}

This section is subdivided into two subsections. In the first we present the estimates for the coverage rate, the dissimilarity index, and our opportunity index (respectively, $\hat{\mu}, \hat{D}$, and $\hat{O}$ ). All results are presented separately by children's age.

In the second subsection, we present results for the human opportunity index and the associated measures of coverage and dissimilarity. The comparison of the two opportunity measures is informative about the extent to which non-attendance to daycare or preschool is voluntary.

\subsection{Opportunity Index}

Figure 1 displays a visual summary of the opportunity measure we use in this study, calculated for children aged 0-3 years old attending daycare or not attending by parental choice in 2006. The horizontal axis contains the percentiles of children according to the (ascending) ordering of $\mathrm{p}(\mathrm{X})$, while the vertical axis measures $\mathrm{p}(\mathrm{X})$.

\footnotetext{
${ }^{12}$ It can be argued that some of these variables, such as per capita family income, are endogenous from the standpoint of the family. In this paper, we follow the opportunity literature and include them in the set of circumstances because they are beyond children's control.

${ }^{13}$ To capture location, Barros et al. (2009) used only a dummy variable indicating whether children lived in an urban or rural area.
} 


\section{IBRE}

Instituto Brasileiro
de Economia

The horizontal line corresponds to $\mu$, the shaded area above it represents the proportion of unequally allocated opportunities (T) and the shaded area below it measures the opportunity index $(\mathrm{O})$.

Figure 1 shows that the average coverage rate for daycare was roughly $50 \%$ in 2006. Coverage was slightly higher than $80 \%$ among the group of circumstances with the highest probability of having the option to attend daycare and thus significantly below full coverage. The figure also shows that a significant fraction of the available opportunities is unequally allocated.

Figure 1: Percentage of children 0-3 years old attending daycare or not attending by parental choice: Brazil, $2006(\%)$

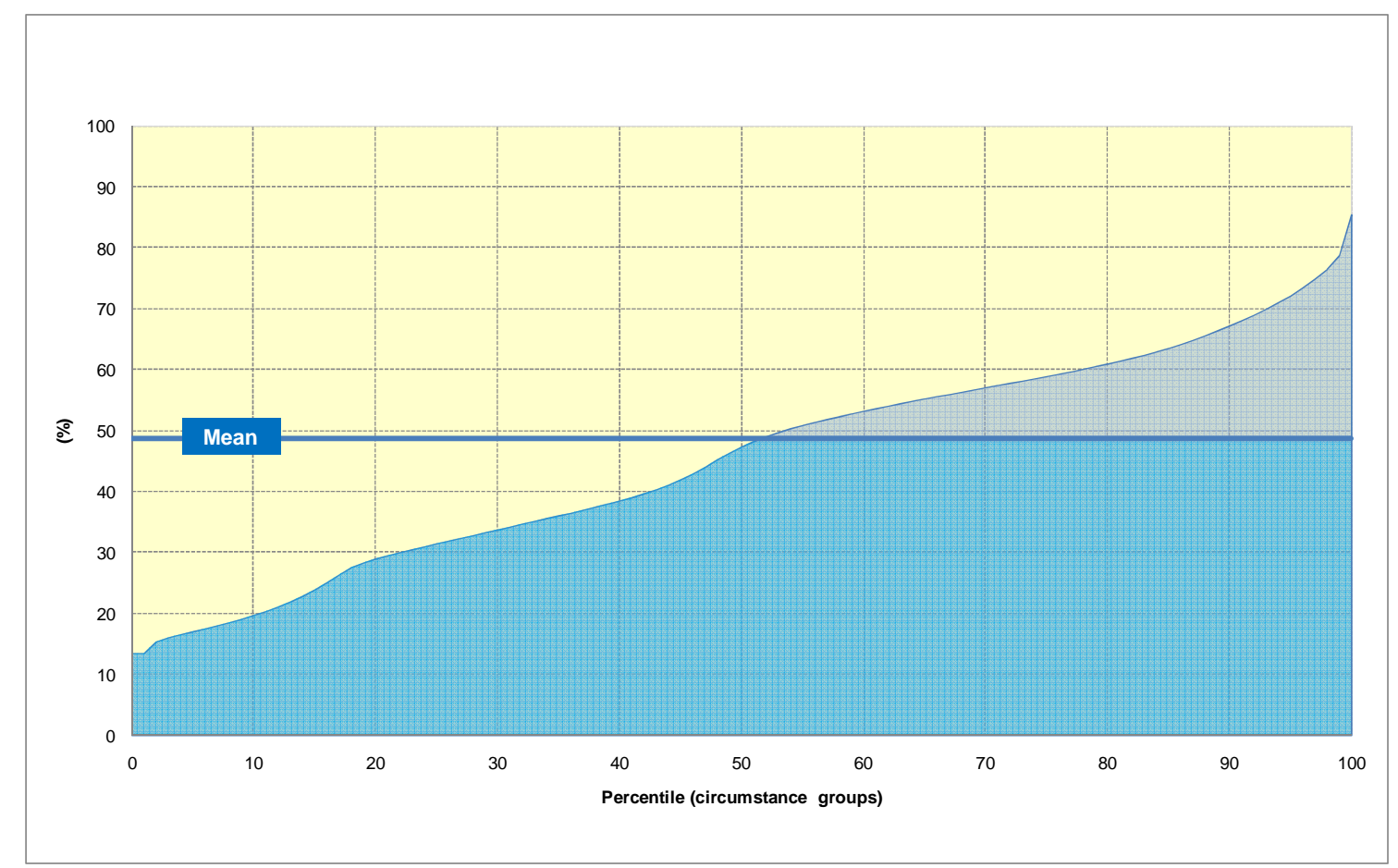

Note: Estimates from Pesquisa Nacional por Amostra de Domicílios, 2006. 


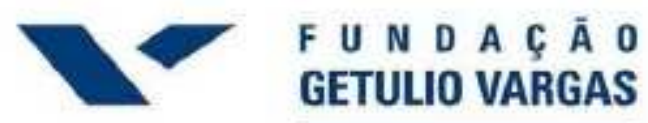

\section{IBRE}

Instituto Brasileiro

de Economia

Figure 2 presents the results for children aged 4-6 years old attending preschool or not attending by parental choice in 2006 . The figure shows that the average coverage rate of preschool is $73 \%$, which is considerably higher than the one for daycare. Moreover, among the group of circumstances with the highest probability of preschool attendance coverage is above $90 \%$ and thus close to full coverage. The comparison of Figures 1 and 2 shows that the fraction of the available opportunities that are unequally allocated is considerably smaller for preschool than for daycare.

Table 4 presents results for the average probability, dissimilarity index and the opportunity index for children aged 0-3 years old attending daycare or not attending by parental choice in 2006. The results are presented for each age and for the 0-3 age group taken as a whole. 


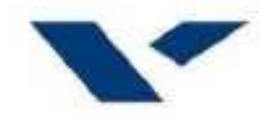

\section{IBRE}

Instituto Brasileiro

de Economia

\section{Figure 2: Percentage of children 4-6 years old attending preschool or not attending} by parental choice: Brazil, $2006(\%)$

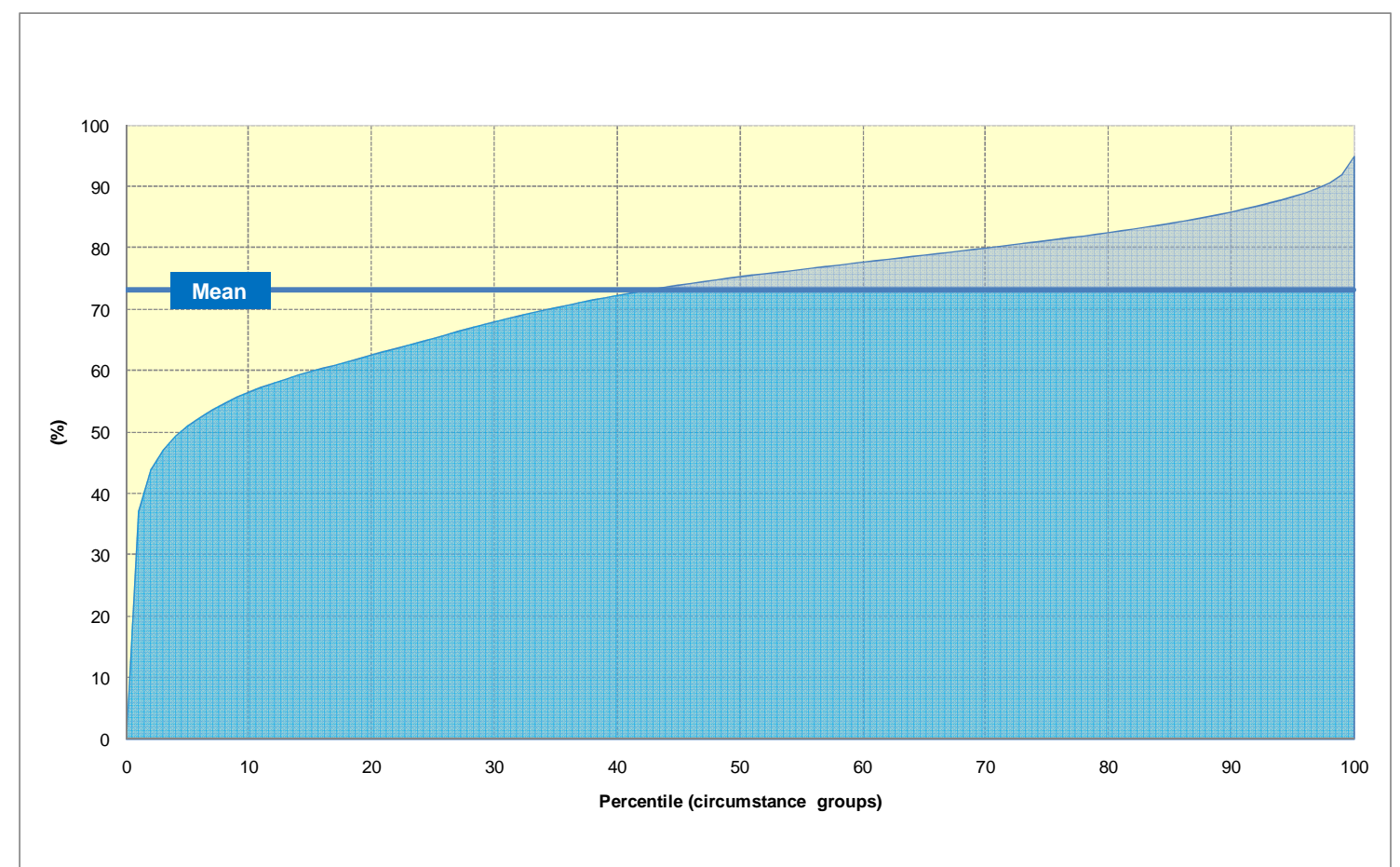

Note: Estimates from Pesquisa Nacional por Amostra de Domicílios, 2006.

Table 4 shows that the average probability and the opportunity index increase with age, whereas the dissimilarity index decreases with age. For instance, the opportunity index increases from $35 \%$ for children aged 0 years old to $51 \%$ for children aged 3 years old. This change reflects the increase in average probability from $43 \%$ to $58 \%$ and a reduction in the dissimilarity index from $19 \%$ to $12 \%$ between the two age categories. 


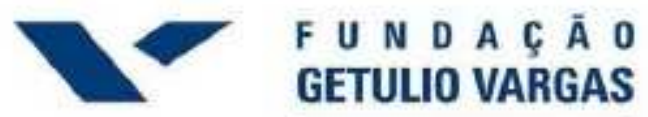

IBRE

Instituto Brasileiro

de Economia

Table 4: Opportunity Index for children 0-3 years old attending daycare or not attending by parental choice: Brazil, $2006(\%)$

\begin{tabular}{lccc}
\hline Age & Average Probability & Dissimilarity Index & Opportunity Index \\
\hline $\mathbf{0}$ years old & 42.9 & 18.6 & 34.9 \\
$\mathbf{1}$ year old & 45.1 & 18.3 & 36.8 \\
$\mathbf{2}$ years old & 48.9 & 16.5 & 40.8 \\
$\mathbf{3}$ years old & 57.5 & 12.0 & 50.6 \\
$\mathbf{0 - 3}$ years old & 48.7 & 15.6 & 41.0 \\
\hline
\end{tabular}

Note: Estimates from Pesquisa Nacional por Amostra de Domicílios, 2006.

Table 5 presents results for the average probability, dissimilarity index and the opportunity index for children aged 4-6 years old attending preschool or not attending by parental choice in 2006. The results are presented for each age and for the 4-6 age group.

Table 5: Opportunity Index for children 4-6 years old attending preschool or not attending by parental choice: Brazil, 2006 (\%)

\begin{tabular}{lccc}
\hline Age & Average Probability & Dissimilarity Index & Opportunity Index \\
\hline 4 years old & 72.4 & 8.4 & 66.3 \\
5 years old & 82.2 & 5.3 & 77.9 \\
6 years old & 65.4 & 4.6 & 62.4 \\
$4-6$ years old & 73.1 & 6.9 & 68.1 \\
\hline
\end{tabular}

Note: Estimates from Pesquisa Nacional por Amostra de Domicílios, 2006.

Table 5 shows that the average probability and the opportunity index are higher for 5 year-old than for 4-year old children, whereas the dissimilarity index decreases. In contrast, our measure of opportunity is lower for 6 year-old children than for 5 year-old. 


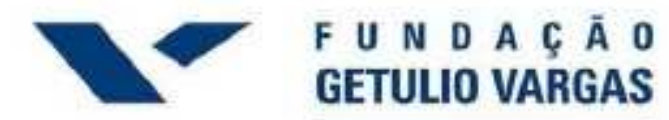

IBRE

Instituto Brasileiro

de Economia

This is due to the fact that some parents decide to enroll their 6 year-old children in primary school instead of preschool.

The comparison of Tables 4 and 5 shows that the opportunity index is considerably higher for preschool than for daycare. Whereas opportunity for children aged 0-3 years old was $41 \%$ in 2006, the corresponding index for children aged 4-6 years old was $68 \%$. This difference is due both to a higher average probability ( $73 \%$ for preschool and $49 \%$ for daycare) and a lower dissimilarity index (7\% for preschool and $16 \%$ for daycare).

In summary, the results show that opportunity is considerably higher for preschool than for daycare, even after taking into account the fact that non-attendance may be a voluntary decision and not necessarily an indicator of lack of opportunity.

\subsection{Comparison with Human Opportunity Index}

As discussed above, we believe that our opportunity index is more appropriate than the human opportunity index for the measurement of opportunity in the context of daycare and preschool. Since it is not clear if D\&P services are a basic opportunity, it is possible that the fact that parents do not enroll their children in daycare or preschool does not reflect a lack of opportunity, but a parental choice given their preferences and constraints. Hence, the comparison of the two opportunity measures is informative about the extent to which non-attendance in daycare or preschool is voluntary.

Figure 3 displays a visual summary of the human opportunity index for children aged 0-3 years old attending daycare in 2006. The figure shows that the mean coverage rate for daycare is considerably smaller (around 15\%) when we consider the human opportunity index instead of our opportunity measure (roughly 50\%). Moreover, the fraction of the available opportunities that are unequally allocated is considerably higher for the human opportunity measure. 


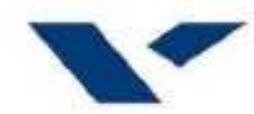

\section{IBRE}

Instituto Brasileiro

de Economia

Figure 3: Percentage of children 0-3 years old attending daycare: Brazil, 2006 (\%)

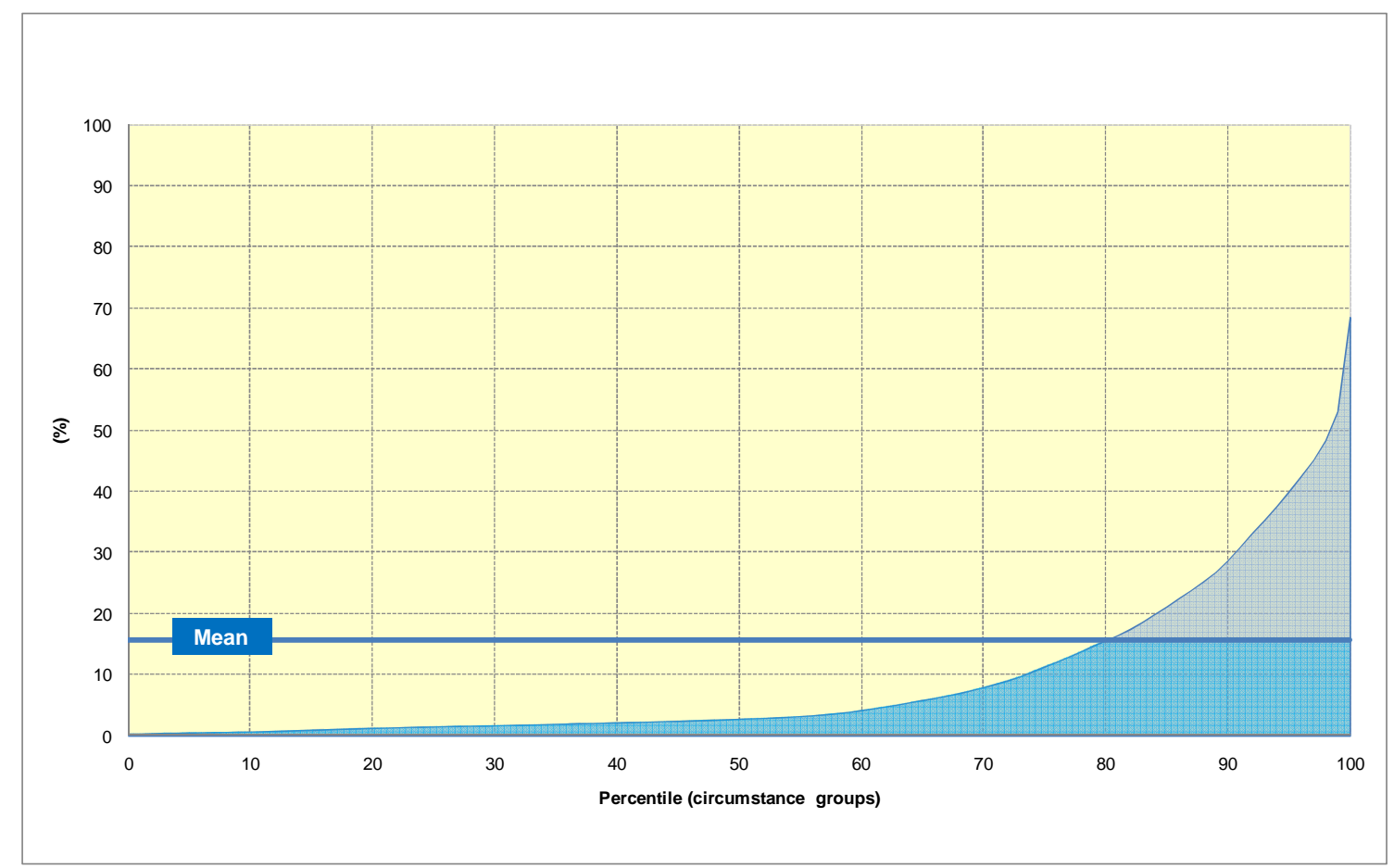

Note: Estimates from Pesquisa Nacional por Amostra de Domicílios, 2006.

These results suggest that, in the context of daycare services, the human opportunity index overestimates the degree of inequality of opportunity in society, because it associates non-attendance with lack of opportunity, whereas it may also result from a voluntary parental decision.

Figure 4 presents the results for the human opportunity index for children aged 4-6 years old attending preschool in 2006. The figure shows that when we use the human opportunity attendance-based measure, the mean coverage rate of preschool, around $65 \%$, is close to our option-based measure, which is around $70 \%$. This is due to the fact that a small fraction of parents choose not to enroll their children in preschool, and it suggests that preschool may be considerably closer to a basic opportunity than daycare. 


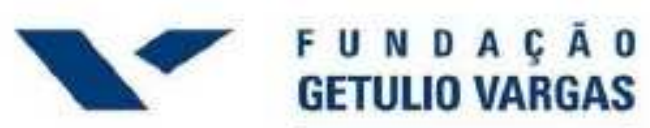

\section{IBRE}

Instituto Brasileiro

de Economia

Figure 4: Percentage of children 4-6 years old attending preschool: Brazil, 2006 (\%)

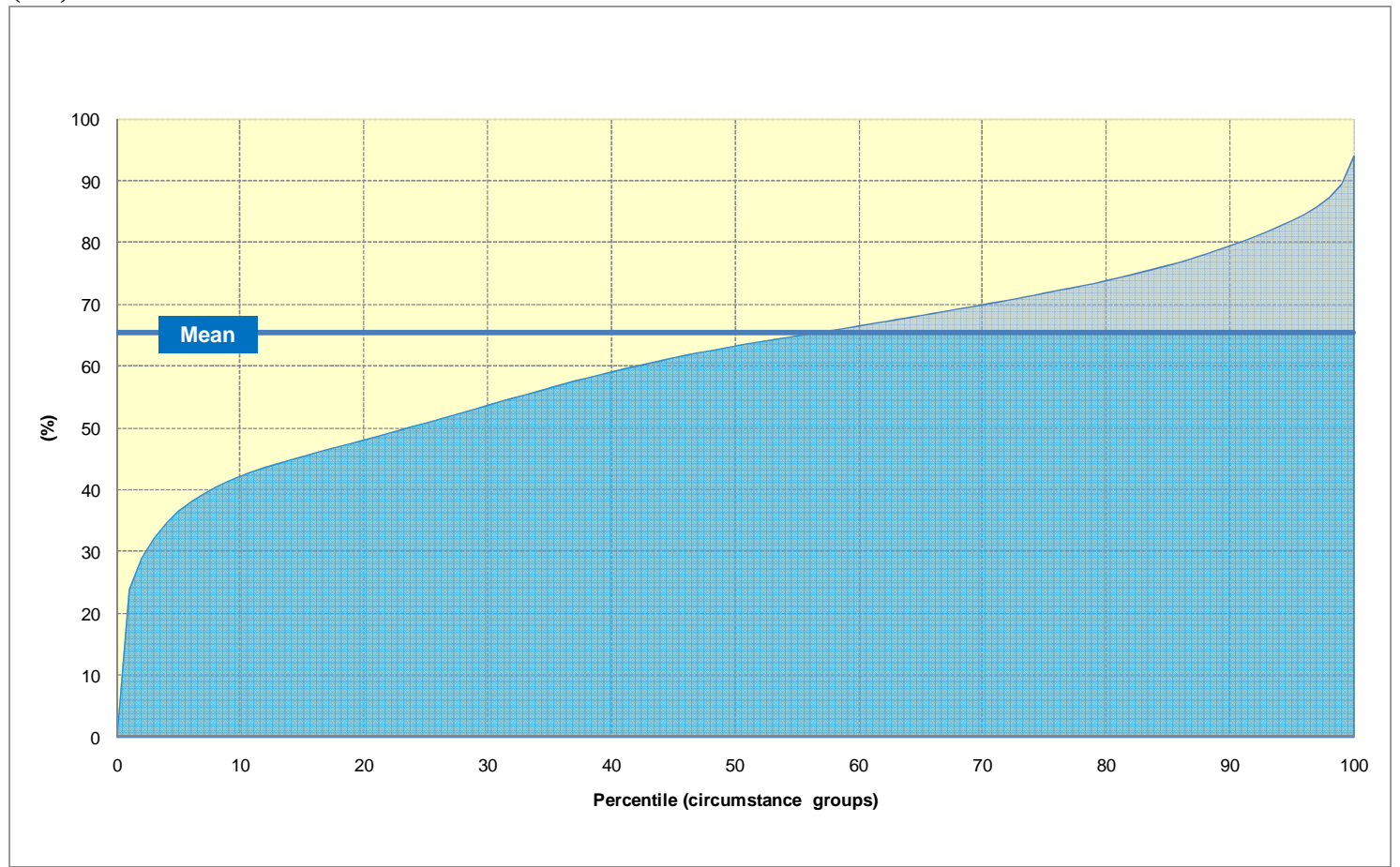

Note: Estimates from Pesquisa Nacional por Amostra de Domicílios, 2006.

Table 6 presents results for the human opportunity index and the associated average probability and dissimilarity index for children aged 0-3 years old attending daycare in 2006. As we obtained for our opportunity index, both the average probability and the human opportunity index increase with age, whereas the dissimilarity index decreases with age. 
Table 6: Human Opportunity Index for children 0-3 years old attending daycare: Brazil, $2006(\%)$

\begin{tabular}{lccc}
\hline Age & Average Probability & Dissimilarity Index & Opportunity Index \\
\hline $\mathbf{0}$ years old & 2.2 & 33.2 & 1.4 \\
$\mathbf{1}$ year old & 7.2 & 36.4 & 4.6 \\
$\mathbf{2}$ years old & 17.7 & 23.5 & 13.5 \\
$\mathbf{3}$ years old & 34.6 & 19.1 & 28.0 \\
$\mathbf{0 - 3}$ years old & 15.6 & 40.3 & 9.3 \\
\hline
\end{tabular}

Note: Estimates from Pesquisa Nacional por Amostra de Domicílios, 2006.

However, as suggested by the figures above, the human opportunity index is much smaller than our opportunity index. Specifically, the comparison of Tables 4 and 6 shows that our measure of opportunity was $41 \%$ in 2006, whereas the human opportunity index was only $9 \%$ in the same year. This suggests that the human opportunity index overestimates the degree of inequality of opportunity in society, because it associates non-attendance to lack of opportunity, whereas it may also result from a choice by the parents.

Table 7 presents results for the human opportunity index and the associated average probability and dissimilarity index for children aged 4-6 years old attending preschool in 2006. The comparison of Tables 6 and 7 shows that the human opportunity index is considerably higher for preschool than for daycare. While opportunity for children aged 0-3 years old was 9\% in 2006, the corresponding index for children aged 4-6 years old was $60 \%$ in the same year. 


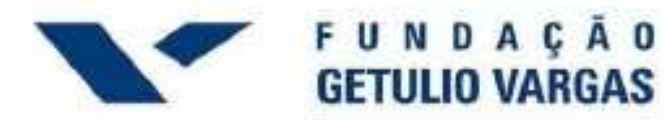

IBRE

Instituto Brasileiro

de Economia

Table 7: Human Opportunity Index for children 4-6 years old attending preschool: Brazil, $2006(\%)$

\begin{tabular}{lccc}
\hline Age & Average Probability & Dissimilarity Index & Opportunity Index \\
\hline $\mathbf{4}$ years old & 58.0 & 13.0 & 50.5 \\
$\mathbf{5}$ years old & 75.0 & 7.7 & 69.2 \\
$\mathbf{6}$ years old & 63.3 & 5.3 & 59.9 \\
$\mathbf{4 - 6}$ years old & 65.5 & 9.0 & 59.6 \\
\hline
\end{tabular}

Note: Estimates from Pesquisa Nacional por Amostra de Domicílios, 2006.

The comparison of Tables 5 and 7 shows that the human opportunity and our opportunity index are similar for preschool. For instance, in 2006 the human opportunity index was $60 \%$, which is close to our opportunity measure of $68 \%$ in the same year. Moreover, the difference between the two indexes decreases with age. For instance, for children aged 4 years old, the difference was 15 percentage points $(66 \%$ and $51 \%$ for our measure and the human opportunity index, respectively), whereas for children aged 5 years old the difference declines to 9 p.p. (78\% and 69\%).

Figure 5 compares our opportunity index and the human opportunity index. The figure shows large differences between our opportunity index and the human opportunity index for children aged 0-3 years old and considerably smaller differences for children aged 4-6 years old. This is due to the fact that a significant fraction of parents of children aged 0-3 years old choose not to enroll their children in daycare. On the other hand, as children's age increases, the proportion of children that do not attend school by parental choice declines significantly, which suggests that preschool may be closer to a basic opportunity than daycare. 


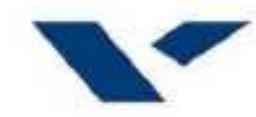

\section{IBRE}

Instituto Brasileiro

de Economia

Figure 5: Opportunity Index and Human Opportunity Index by Age: Brazil, 2006 (\%)

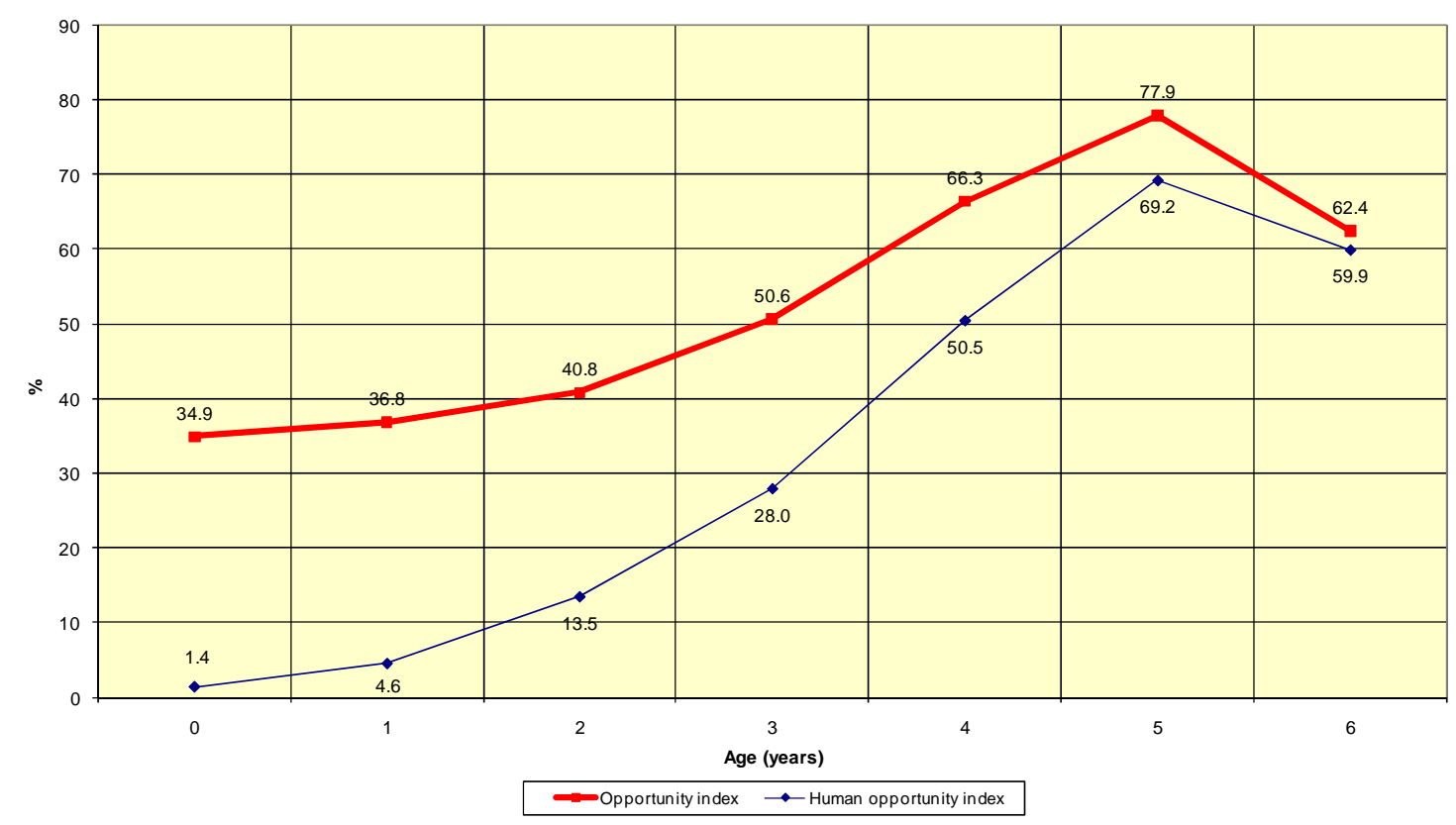

Note: Estimates from Pesquisa Nacional por Amostra de Domicílios, 2006.

As mentioned before, both measures of opportunity are lower for 6 year-old children than for 5 year-old. This is due to the fact that some parents decide to enroll their 6 year-old children in primary school instead of preschool.

\section{Opportunity Profiles}

In this section, we present results from an exercise that traces the profile of what can be called the most- and the least-disadvantaged groups in terms of the opportunity to access daycare and preschool services. The idea is to trace out the profile of children that are respectively at the bottom and the top of the probability distribution of opportunities in terms of the circumstance variables. 


\section{GETULIO VARGAS}

\section{IBRE}

Instituto Brasileiro

de Economia

Specifically, we perform the exercise in the following three steps. ${ }^{14}$ First, we rank in increasing order the predicted probabilities of having the opportunity to attend a pre-primary establishment (i.e. the $\hat{p}_{i}$ 's, see subsection 2.2). Second, we identify the most-disadvantaged (least-disadvantaged) group by summing the children from the bottom (top) of the distribution up to the point where they represent 10 percent of the overall population of children of the corresponding age group. Third, we compute the distribution of children for each circumstance variable in the most- and leastdisadvantaged groups of opportunity. We believe this exercise can be useful for policy purposes to the extent that it informs policymakers the profile of children that have the lowest opportunity to attend a pre-primary establishment.

Table 8 presents the profiles for the 0 to 3 and 4 to 6 age groups. The table reveals that there are considerable differences between the most- and leastdisadvantaged groups for both age cohorts. For instance, while around $28 \%$ of children are white in the most-disadvantaged group, this number rises to more than $71 \%$ in the least-disadvantaged group. The urban/rural division is also stark, with almost no children in the least-advantaged group living in rural areas, in contrast with around $70 \%$ in the most-disadvantaged group. More than $90 \%$ of children in the most opportunitydeprived group live in non-metropolitan areas, in comparison with around $60 \%$ in the least opportunity-deprived group.

Another pronounced difference occurs in terms of the educational level of the head of the household. More than $93 \%$ of children in the most-disadvantaged group live in households where the head did not complete primary education, in comparison to less than $19 \%$ in the least-disadvantaged group. Not surprisingly, the vast majority of opportunity-deprived children are below the median per capita income (more than

\footnotetext{
${ }^{14}$ The method implemented here is based on Ferreira and Gignoux (2008) and Barros et al. (2009, chapter 4).
} 


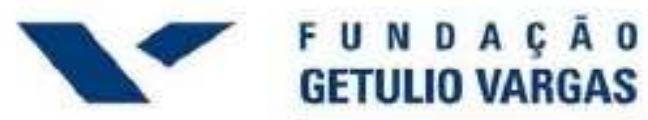

\section{IBRE}

Instituto Brasileiro

de Economia

94\%), whereas less than $30 \%$ in the least-disadvantaged group live in households with per capita income below the median.

Regional differences are also marked, especially for 0-3 year old children. For this age group, $95 \%$ of disadvantaged children live in the poor Northeast and North regions, whereas the rich South and Southeast are the area of residence of $98 \%$ of the least-disadvantaged children. For the 4-6 year old group, the concentration of children in the two poorest regions is less pronounced in the most-disadvantaged group (54\%), whereas $75 \%$ of children in the least-disadvantaged group live in the two richest regions.

Table 8: Most-disadvantaged and least-disadvantaged circumstance groups for children attending daycare (preschool) or not attending by parental choice: Brazil, 2006 (\%) 


\begin{tabular}{|c|c|c|c|c|}
\hline \multirow[b]{2}{*}{ Circumstance } & \multicolumn{2}{|c|}{ Most-disadvantaged } & \multicolumn{2}{|c|}{ Least-disadvantaged } \\
\hline & $0-3$ years old & 4-6 years old & $0-3$ years old & 4-6 years old \\
\hline \multicolumn{5}{|l|}{$\overline{\text { Gender }}$} \\
\hline Male & 50.8 & 50.2 & 53.3 & 54.9 \\
\hline Female & 49.2 & 49.8 & 46.7 & 45.1 \\
\hline \multicolumn{5}{|l|}{ Race } \\
\hline White & 27.5 & 28.5 & 79.7 & 71.8 \\
\hline Non-white & 72.5 & 71.5 & 20.3 & 28.2 \\
\hline \multicolumn{5}{|l|}{ Area } \\
\hline Urban & 28.4 & 31.1 & 99.7 & 99.8 \\
\hline Rural & 71.6 & 68.9 & 0.3 & 0.2 \\
\hline \multicolumn{5}{|l|}{ Region } \\
\hline North & 30.5 & 16.4 & 0.0 & 0.6 \\
\hline Northeast & 64.8 & 37.7 & 1.0 & 23.5 \\
\hline Southeast & 0.0 & 6.9 & 67.2 & 69.2 \\
\hline South & 0.0 & 15.6 & 30.8 & 5.8 \\
\hline Midwest & 4.7 & 23.4 & 1.1 & 1.0 \\
\hline \multicolumn{5}{|l|}{ Type of municipality } \\
\hline Metropolitan area & 5.1 & 10.0 & 41.9 & 40.4 \\
\hline Non-metropolitan area & 94.9 & 90.0 & 58.1 & 59.6 \\
\hline \multicolumn{5}{|l|}{ Schooling of the head } \\
\hline None & 42.0 & 39.0 & 0.1 & 0.1 \\
\hline Primary incomplete & 51.8 & 54.9 & 18.2 & 13.4 \\
\hline Secondary incomplete & 5.0 & 4.4 & 19.1 & 19.4 \\
\hline At least secondary complete & 1.2 & 1.7 & 62.6 & 67.1 \\
\hline \multicolumn{5}{|l|}{ Parenthood status } \\
\hline Single parent & 21.0 & 13.0 & 18.5 & 21.9 \\
\hline Both parents & 79.0 & 87.0 & 81.5 & 78.1 \\
\hline \multicolumn{5}{|l|}{ Number of siblings } \\
\hline None & 32.6 & 13.3 & 55.1 & 48.5 \\
\hline Exactly 1 & 26.9 & 24.3 & 34.9 & 42.2 \\
\hline More than 2 & 40.5 & 62.4 & 10.0 & 9.3 \\
\hline \multicolumn{5}{|l|}{ Quartile of income distribution } \\
\hline First & 81.0 & 72.9 & 8.5 & 8.3 \\
\hline Second & 16.2 & 21.6 & 20.7 & 20.2 \\
\hline Third & 2.6 & 4.6 & 23.2 & 29.4 \\
\hline Fourth & 0.2 & 0.8 & 47.6 & 42.1 \\
\hline
\end{tabular}

Note: Estimates from Pesquisa Nacional por Amostra de Domicílios, 2006. 


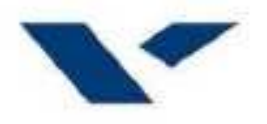

\section{IBRE}

Instituto Brasileiro

de Economia

The proportion of children that have more than two siblings is much more pronounced at the bottom ( $41 \%$ for the 0-3 group and $62 \%$ for the 4-6 group) than at the top (around $10 \%$ for both age groups) of the opportunity profile. However, the proportion of 0-3 year old children living with only one parent in the mostdisadvantaged group is not much higher than in the top group. For the 4-6 year old group, the proportion of children living with a single parent is higher for the leastdisadvantaged. Moreover, there is no clear pattern in terms of the gender of the child: the proportion of boys attending daycare or preschool is around 50 percent for the mostdisadvantaged group, and close to $54 \%$ for the least-disadvantaged.

\section{Conclusion}

In this paper we measured the degree of inequality of opportunity in daycare and preschool services in Brazil. For this purpose, we constructed an opportunity index that modifies the human opportunity index proposed by Barros et al. (2008a) and Barros et al. (2008b), and used in Barros et al. (2009) to measure inequality in basic opportunities in Latin America and the Caribbean.

In the construction of the human opportunity index proposed by these authors, access to schooling is equivalent to actual attendance. However, we argue that the relevant measure of opportunity in daycare and preschool services in Brazil is the option to attend daycare or preschool and not attendance per se. This measure is consistent with several changes in pre-primary education legislation that have been enacted in Brazil since the late eighties.

We thus constructed an opportunity measure that included not only attendance but also the choice not to enroll children in daycare or preschool, using data from a supplementary questionnaire that was included in the 2006 version of PNAD. This supplement asked the main reason why children were not attending daycare or 


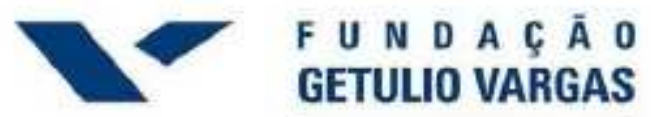

IBRE

Instituto Brasileiro

de Economia

preschool, one of the reasons being that the parents did not want their children to attend daycare or preschool.

It is possible that parents who answer that they do not want their children to attend daycare or preschool are in fact restricted by lack of income or vacancies in daycare and preschool establishments. Even though this limitation of the analysis should be considered in the interpretation of our results, we provided some evidence that the relationship between the parental response "do not want children to attend" and variables such as income and age of the child is significantly different from the one between these variables and the motives capturing lack of resources or vacancies.

The results show that there are large differences between our opportunity index and the human opportunity index for children aged 0-3 years old and considerably smaller differences for children aged 4-6 years old. This is due to the fact that for children aged 0-3 years old there is a significant fraction of parents who prefer not to enroll their children in daycare. On the other hand, as children's age increases, the proportion of children that do not attend school due to parental choice declines significantly, which suggests that preschool may be closer to a basic opportunity than daycare.

The profile comparison of the $10 \%$ most-disadvantaged and least-disadvantaged children indicated large differences for many circumstance variables for both children aged 0-3 and 4-6 years old. In particular, a typical child in the most-disadvantaged group is non-white, lives in a household below the median per capita income and whose head did not complete the primary degree. The opposite applies to children at the top of the opportunity distribution. 


\section{References}

Barros, R. P., Vega, J. M. and Saavedra, J. (2008a). "Measuring Inequality of Opportunities for Children". Discussion Paper. World Bank.

Barros, R. P, Vega, J. M. and Saavedra, J. (2008b). "Measuring the Progress Toward Basic Opportunities for All”. Mimeo.

Barros, R. P, Ferreira, F., Vega, J. M. and Saavedra, J. (2009). Measuring Inequality of Opportunities in Latin America and the Caribbean. The World Bank. Washington, DC.

Becker, G. (1993). Human Capital: A Theoretical and Empirical Analysis with Special Reference to Education. $3^{\text {rd }}$ ed. The University of Chicago Press.

Carneiro, P. and Heckman, J. (2003). "Human Capital Policy” In Heckman, J. Krueger, A. and Friedman, B. Inequality in America: What Role for Human Capital Policies?, MIT Press.

Checchi, D. and Peragine, V. (2010). "Inequality of Opportunity in Italy", Journal of Economic Inequality 8, pp. 429-450.

Cunha, F, Heckman, J., Lochner, L. and Masterov, D. (2006). "Interpreting the Evidence on Life Cycle Skill Formation”. In: Hanushek, E. and Welch, F. (eds). The Handbook of Economics of Education, chapter 12, pp. 697-812.

Cunha, F. and Heckman, J. (2009). "The Economics and Psychology of Inequality and Human Development”. NBER Working Paper no. 14695.

Ferreira, F. and Gignoux, J. (2008). "The Measurement of Inequality of Opportunity: Theory and an Application to Latin America", Policy Research Working Paper 4659, World Bank.

Peragine, V. (2011). "Review of 'Measuring Inequality of Opportunities in Latin America and the Caribbean' by Ricardo Paes de Barros, Francisco H. G. Ferreira, José R. Molinas Vega, and Jaime Saavedra Chanduvi, World Bank and Palgrave Macmillan, 2009”. Journal of Economic Inequality 9, pp. 137-143.

Pistolesi, N. (2009). "Inequality of Opportunity in the Land of Opportunities, 1968-2001”, Journal of Economic Inequality 7, pp. 411-433.

Roemer, J. E. (1998). Equality of Opportunity. Cambridge, Harvard University Press.

Sen, A. (1976). "Real National Income" Review of Economic Studies 43 (1), pp. $19-39$. 